\title{
Single-cell expression profiles of ACE2 and TMPRSS2 reveals potential vertical transmission and fetus infection of SARS-CoV-2
}

\author{
Mengdie Lü̈ ${ }^{1,2}$, Li Qiư ${ }^{3}$, Guangshuai Jia ${ }^{1}$, Rongqun Guo ${ }^{4}$, Qibin Leng ${ }^{1}$ \\ ${ }^{1}$ Affiliated Cancer Hospital and Institute of Guangzhou Medical University, State Key Laboratory of Respiratory \\ Disease, Guangzhou, China \\ ${ }^{2}$ Joint National Laboratory for Antibody Drug Engineering, Key Laboratory of Cellular and Molecular Immunology \\ of Henan Province, Institute of Translational Medicine, School of Basic Medicine, Henan University, Kaifeng, China \\ ${ }^{3}$ Department of Clinical Oncology, Taihe Hospital, Hubei University of Medicine, Shiyan, Hubei, China \\ ${ }^{4}$ Department of Hematology, The First Affiliated Hospital of Zhengzhou University, Zhengzhou, Henan, China
}

Correspondence to: Rongqun Guo, Qibin Leng; email: guorq2007@163.com, https://orcid.org/0000-0002-1238-4772; qbleng@gzhmu.edu.cn

Keywords: COVID-19, SARS-CoV-2, pathogenesis, fetus, placenta

Received: April 16, $2020 \quad$ Accepted: August 22, 2020

Published: October 26, 2020

Copyright: (C) 2020 Lü et al. This is an open access article distributed under the terms of the Creative Commons Attribution License (CC BY 3.0), which permits unrestricted use, distribution, and reproduction in any medium, provided the original author and source are credited.

\section{ABSTRACT}

Morbidity and mortality of coronavirus disease 2019 (COVID-19) is age-dependent. It remains unclear whether vertical severe acute respiratory syndrome coronavirus 2 (SARS-CoV-2) occurs during pregnancy and how such infection will affect fetal development. Here, we performed single-cell transcriptomic analysis of placenta and other tissues from fetuses in comparison with those from adults using public-available datasets. Our analysis revealed that a very small proportion of trophoblast cells expressed the Angiotensin I Converting Enzyme 2 (ACE2) gene, suggesting a low possibility of vertical transmission of SARS-CoV-2 from mother to fetus during pregnancy. We found that the fetal adrenal gland, heart, kidney and stomach were susceptible to SARS-CoV-2 infection, because these organs contained cell clusters that expressed high levels of the ACE2 gene. In particular, a higher proportion of ACE2-expressing cell clusters in the adrenal gland and kidney also expressed the Transmembrane Serine Protease 2 (TMPRSS2) gene compared with other organs. Surprisingly, ACE2-expressing type II alveolar (AT2) equivalent cells were absent in fetal lungs. This is in sharp contrast to adult lungs. As ACE2 expression is regulated by various conditions, including oxygen concentration, inflammation and smoking, caution is warranted to avoid triggering potential ACE2 expression in fetal and placental tissue.

\section{INTRODUCTION}

At present, the worldwide pandemic of SARS-CoV-2 virus have caused serious health, economic and social problems. It is reported that the potential key factors for mortality are an older age and chronic comorbidities [1]. Fever and cough are the most common symptoms, followed by sputum production and fatigue [2]. Consistent with the symptoms, autopsy findings in adults included damage in the lungs, as well as the adrenal gland, blood vessels, gallbladder, heart, kidney and liver [3, 4]. Children are also susceptible to SARS-CoV-2 infection, but have relatively mild symptoms [5]. Recently, a serological SARS-CoV-positive and PCR-negative newborn case was reported [6], suggesting possible vertical transmission of SARS-CoV-2 during pregnancy. Thus, the risk of vertical transmission and the potential pathogenesis of fetuses infected with SARS-CoV-2 merit further investigation. 
Human angiotensin-converting enzyme 2 (ACE2) was reported as the docking and entry receptor of SARS-like coronavirus to invade human cells [7,8]. The ACE2 was also identified as a cellular entry receptor for SARS-CoV-2, which did not use other coronavirus receptors, such as aminopeptidase $\mathrm{N}$ and dipeptidyl peptidase 4 [9]. Moreover, the priming of SARS-CoV-2 spike protein by cellular transmembrane serine protease 2 (TMPRSS2) was shown to be essential for viral entry [10]. Single-cell RNA sequencing (scRNA-seq) analysis has revealed that ACE2 is expressed mainly on AT2 cells in the lungs [11]. The AT2 cells also express many other genes that are involved in viral replication and transmission [12]. Thus, AT2 cells represent the most susceptible cells for SARS-CoV-2 infection in adult lungs. In addition, $A C E 2$ is also expressed in bronchial and nasal epithelial cells, absorptive enterocytes from ileum and colon, liver cholangiocytes and cells from kidney proximal tubules $[11,13,14]$. These studies suggest that SARS-CoV-2 infection may directly contribute to the pathogenesis of respiratory and digestive system diseases in patients with severe COVID-19 infection.

To assess the risk of vertical infection of the fetus during pregnancy, we analyzed ACE2 and TMPRSS2 gene expression in human placenta and fetal tissues compared with adult tissues using publicly-available scRNA-seq datasets (GSE134355) [15]. Our analysis revealed a low level of potential infection of the placenta with SARS-CoV-2. In addition, fetal lungs appear unlikely to be susceptible to SARS-CoV-2 viral infection.

\section{RESULTS}

\section{Few ACE2 expressing trophoblast cells in the placenta indicate a low possibility of vertical transmission of SARS-CoV-2 infection}

The placenta is a transient organ critical for normal embryonic development [16]. To explore the possibility of vertical transmission of SARS-CoV-2 infection during pregnancy, we analyzed single-cell data from the placenta. Nine ACE2-positive cells, which were located in the GATA3-positive population, were detected among 9,852 placenta-derived cells (Figure 1A, 1B). Moreover, the GATA3-positive cell clusters were also enriched for CSH1, KRT19, and COL1A1 expression, markers for trophoblast cells [16-18] (Supplementary Figure 1A). This evidence indicates that SARS-CoV-2 may directly infect trophoblast cells. For example, a recent case report found transplacental transmission of SARS-CoV2 infection, identified by SARS-CoV-2 positive trophoblastic cells in the placenta [19]. Of note, placental barrier trophoblast cells also secrete interferon- $\lambda 1$ to protect the fetus from viral infection [20]. Thus, any conditions that increase ACE2expressing trophoblasts or diminish their ability to secret interferon- $\lambda 1$ will potentially enhance the possibility of vertical infection of SARS-CoV-2.

\section{Fetal lungs and liver are likely not susceptible to SARS-CoV-2 infection}

Lungs are a primary target organ for SARS-CoV-2 infection. In addition, severe pneumonia is the major reason for fatality of patients with COVID-19 infection $[1,14]$. To better understand the potential pathogenesis of COVID-19 infection in the fetus, we analyzed scRNA-seq data from the GEO database (GSE134355: lungs) (Table 1). A total of 57,011 cells from five samples were harvested after merge using the Seurat $\mathrm{R}$ package. After filtration, 56,726 cells qualified for further data analysis, with 18,951 from fetal lungs tissue. Cell clusters were identified using reported markers, namely $C A V 1$ and $A G E R$ (AT1 cells) [21], SFTPC, ABCA3 (AT2 cells), NKX2-1, FOXA2 [22], PTPRC (hematopoietic cells), COL1A1 (fibroblast cells) and CLDN5 (endothelial cells) [23] (Supplementary Figure 1B). Among the clusters, adult AT2 cells widely expressed the TMPRSS 2 gene compared with the ACE2 gene. In contrast, equivalent AT2 cells in the fetus did not express TMPRSS2. Noticeably, a small fraction of progenitor cells $(N K X 2-1+)$ in fetal lungs expressed TMPRSS2 (Figure 1C, 1E, Supplementary Figure 1B). To our surprise, ACE2-positive cells were absent in the fetus, whereas $0.66 \%$ of adult AT2 cells expressed the ACE2 gene (Figure 1C, 1D, Figure 2). Furthermore, TMPRSS2 alone without ACE2 will not mediate SARS-CoV-2 infection efficiently. Therefore, these results suggest that fetal lungs are unlikely to be susceptible to SARS-CoV-2 infection, because of the absence of ACE2-expressing cells.

To explore the susceptibility of the fetal liver to SARS-CoV-2 infection, we analyzed scRNA-seq data from five adult samples and two fetal samples. In total, 28,303 adult cells and 18,072 fetal cells were acquired after quality control screening. Although ten ACE2expressing cells were detected in CAVI-positive clusters from the adult liver, all fetal liver cells were found to be ACE2-negative (Figure 3A, 3B, Supplementary Figure 1C). TMPRSS2 was also exclusively detected in the CAVI-positive cluster of adult cells (Figure 3A, 3C, Supplementary Figure 1C). The expression pattern of ACE2 and TMPRSS 2 genes in the $C A V 1$-positive cluster was consistent with the finding that liver cholangiocytes were associated with liver injury in COVID-19 patients [24, 25]. Thus, our results suggest that adult liver but not fetal liver is susceptible to SARS-CoV-2 infection. 
Stomach but not pancreas is susceptible to SARSCoV-2 infection

It was reported that $A C E 2$ is expressed in colonic epithelial cells and may be involved in SARS-CoV-2 infection [26]. To further investigate its expression pattern in the digestive system, we analyzed scRNA-seq datasets from the pancreas and stomach. In 22,479 adult stomach cells and 12,602 fetal stomach cells, a small fraction of cells expressed ACE2 and TMPRSS2 (Figure $3 \mathrm{D}-3 \mathrm{~F})$. The percentage of ACE2-positive stomach cells was higher in the fetus than in adult cells (27/12,602 vs 6/22,479 ACE2+, respectively) (Figure 2). These $A C E 2$-expressing cells were mainly fibroblasts ( $D C N$ - and VIM-positive) and epithelium cells (EPCAM-positive) (Supplementary Figure 1D) [27]. In contrast, these $A C E 2$-expressing cells were nearly absent in both the adult and fetal pancreas (Figure 3G, 3H). Expression of TMPRSS2 was found in both pancreas and stomach tissues from adults and to a lesser extent from fetuses (Figure 3F, 3I). These data implied that adult and fetal stomach tissue is likely to be susceptible to SARS-CoV-2 viral infection. In comparison, the pancreas is less likely to be susceptible to infection.

SARS-CoV-2 infection likely directly contributes to heart injury but may not directly impair muscle tissue

Heart injury was highly correlated with poor prognosis of adult COVID-19 patients, probably because of direct virus infection through ACE2 [28, 29]. We analyzed the scRNA-seq dataset of adult and fetal heart tissues to
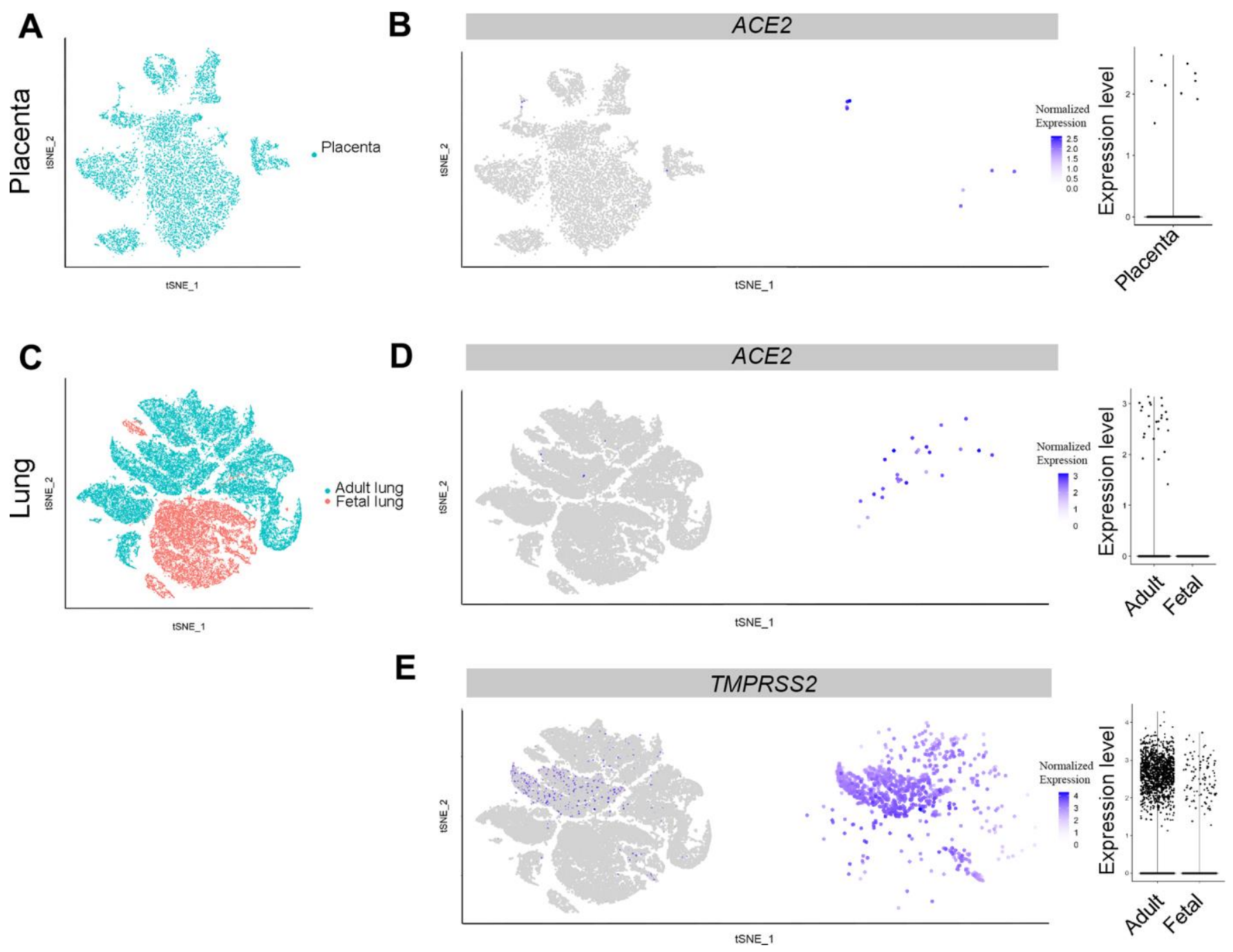

Figure 1. Single-cell analysis of lungs and placenta. (A) t-distributed stochastic neighbor embedding (TSNE) plot showing sub-clusters of placenta cells, and (B) ACE2 expression in placenta. (C) TSNE plot showing sub-clusters of lung cells, (D) ACE2 and (E) TMPRSS2 expression in lungs from the adult and fetal groups. 
Table 1. Description of sample information used in this study.

\begin{tabular}{|c|c|c|c|c|}
\hline Tissue & GSM_ID & Type & Age & Sex \\
\hline Lung & GSM4008628 & Adult & $21 y$ & M \\
\hline Lung & GSM4008629 & Adult & $21 y$ & $\mathrm{~F}$ \\
\hline Lung & GSM4008630 & Adult & $49 y$ & $\mathrm{~F}$ \\
\hline Lung & GSM4008631 & Adult & $49 y$ & $\mathrm{~F}$ \\
\hline Lung & GSM4008632 & Adult & $49 y$ & $\mathrm{~F}$ \\
\hline Lung & GSM4008633 & Adult & $49 y$ & $\mathrm{~F}$ \\
\hline Lung & GSM4008699 & Fetal & $12 w$ & $\mathrm{~F}$ \\
\hline Lung & GSM4008700 & Fetal & $11 \mathrm{w}$ & $\mathrm{F}$ \\
\hline Heart & GSM3980138 & Adult & $52 y$ & $\mathrm{M}$ \\
\hline Heart & GSM3980139 & Adult & $47 y$ & $\mathrm{~F}$ \\
\hline Heart & GSM4008686 & Fetal & $12 w$ & $\mathrm{~F}$ \\
\hline Heart & GSM4008687 & Fetal & $11 \mathrm{w}$ & $\mathrm{F}$ \\
\hline Kidney & GSM4008619 & Adult & $66 y$ & M \\
\hline Kidney & GSM4008620 & Adult & $41 \mathrm{y}$ & $\mathrm{M}$ \\
\hline Kidney & GSM4008621 & Adult & $57 y$ & M \\
\hline Kidney & GSM4008622 & Adult & $57 y$ & M \\
\hline Kidney & GSM4008693 & Fetal & $13 w$ & $\mathrm{M}$ \\
\hline Kidney & GSM4008694 & Fetal & $11 \mathrm{w}$ & M \\
\hline Kidney & GSM4008695 & Fetal & $12 \mathrm{w}$ & M \\
\hline Kidney & GSM4008696 & Fetal & $11 w$ & $\mathrm{~F}$ \\
\hline Adrenal & GSM3943047 & Adult & $36 y$ & M \\
\hline Adrenal & GSM3943048 & Adult & $23 y$ & $\mathrm{~F}$ \\
\hline Adrenal & GSM4008675 & Fetal & $12 \mathrm{w}$ & M \\
\hline Adrenal & GSM4008676 & Fetal & $14 w$ & $\mathrm{M}$ \\
\hline Adrenal & GSM4008677 & Fetal & $12 \mathrm{w}$ & M \\
\hline Adrenal & GSM4008720 & Neonatal & $6 \mathrm{~d}$ & $\mathrm{~F}$ \\
\hline Adrenal & GSM4008721 & Neonatal & $6 \mathrm{~d}$ & $\mathrm{~F}$ \\
\hline Liver & GSM4008623 & Adult & $21 \mathrm{y}$ & $\mathrm{F}$ \\
\hline Liver & GSM4008624 & Adult & $22 y$ & $\mathrm{~F}$ \\
\hline Liver & GSM4008625 & Adult & $52 y$ & $\mathrm{M}$ \\
\hline Liver & GSM4008626 & Adult & $23 y$ & $\mathrm{~F}$ \\
\hline Liver & GSM4008627 & Adult & $24 y$ & $\mathrm{~F}$ \\
\hline Liver & GSM4008697 & Fetal & $26 w$ & $\mathrm{~F}$ \\
\hline Liver & GSM4008698 & Fetal & $27 w$ & $\mathrm{~F}$ \\
\hline Muscle & GSM4008634 & Adult & $63 y$ & M \\
\hline Muscle & GSM4008703 & Fetal & $12 \mathrm{w}$ & M \\
\hline Stomach & GSM4008651 & Adult & $45 y$ & M \\
\hline Stomach & GSM4008652 & Adult & $59 y$ & $\mathrm{M}$ \\
\hline Stomach & GSM4008653 & Adult & $62 y$ & $\mathrm{M}$ \\
\hline Stomach & GSM4008654 & Adult & $62 y$ & $\mathrm{M}$ \\
\hline Stomach & GSM4008655 & Adult & $62 y$ & M \\
\hline Stomach & GSM4008712 & Fetal & $7 \mathrm{w}$ & $\mathrm{F}$ \\
\hline
\end{tabular}




\begin{tabular}{lcccc} 
Tissue & GSM_ID & Type & Age & Sex \\
Stomach & GSM4008713 & Fetal & $11 \mathrm{w}$ & F \\
Pancreas & GSM4008637 & Adult & $43 \mathrm{y}$ & $\mathrm{F}$ \\
Pancreas & GSM4008704 & Fetal & $26 \mathrm{w}$ & F \\
Pancreas & GSM4008705 & Fetal & $11 \mathrm{w}$ & F \\
Pancreas & GSM4008706 & Fetal & $11 \mathrm{w}$ & - \\
Placenta & GSM4008722 & Placenta & $10 \mathrm{w}$ & F \\
\hline
\end{tabular}

A

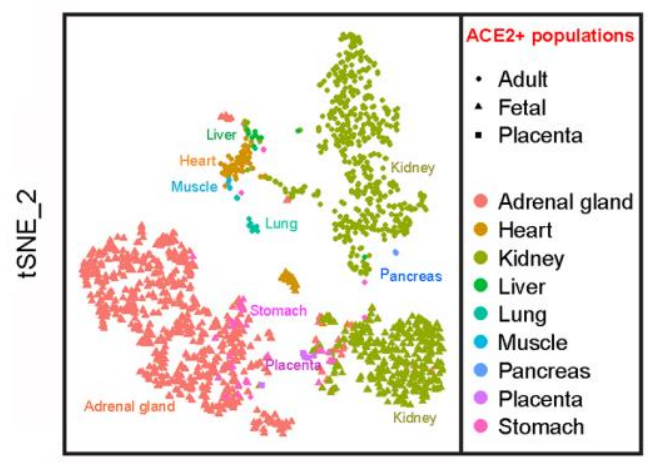

tSNE_1

C

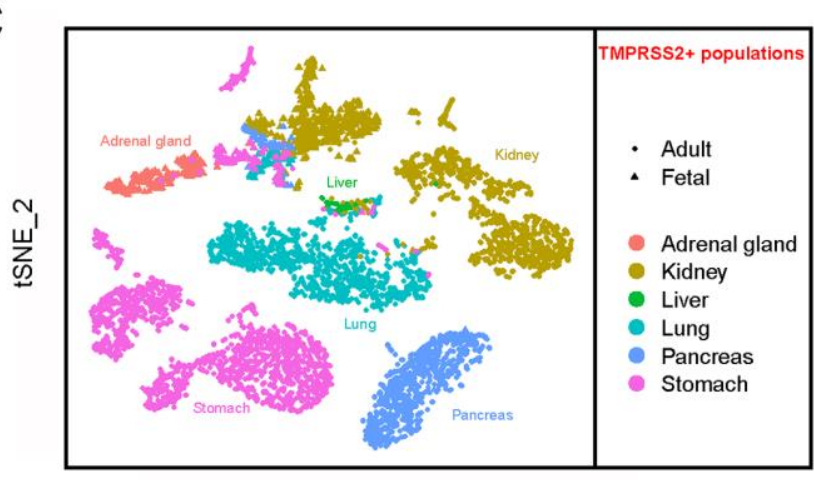

tSNE_1

E

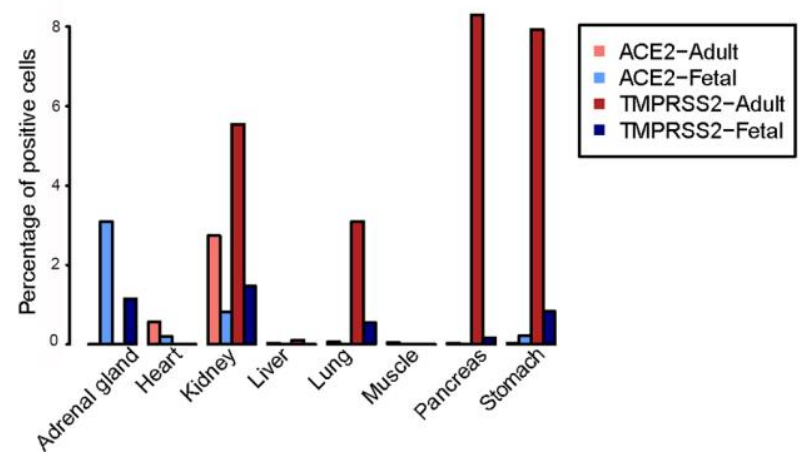

B ACE2

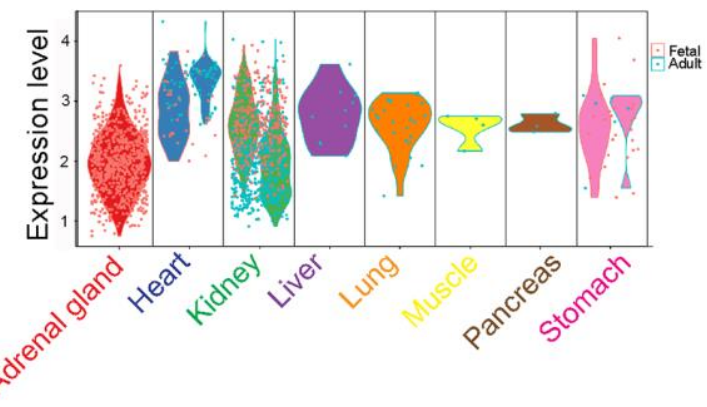

D

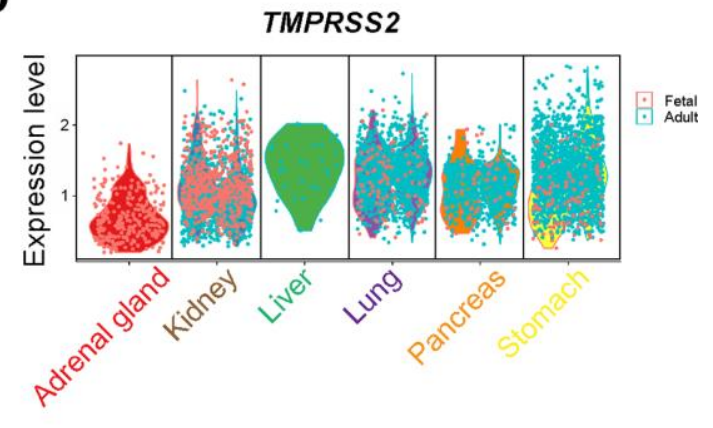

Figure 2. Profiling of ACE2- and TMPRSS2-positive cells in different tissues. (A) t-distributed stochastic neighbor embedding (TSNE) plot of ACE2-positive cells. Cells from the merged adult, fetal and placenta groups are indicated by different dot shapes. (B) Violin plot of ACE2 expression in different tissues from the adult and fetal groups. (C) TSNE plot of TMPRSS2-positive cells. Cells from the merged adult, fetal and placenta groups are indicated by different dot shapes. (D) Violin plot of TMPRSS2 expression in different tissues from the adult and fetal groups. (E) Bar plot showing the percentage of cells expressing ACE2 and TMPRSS2 in the adult and fetal groups. 


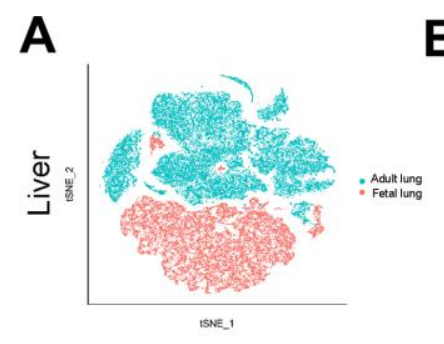

B
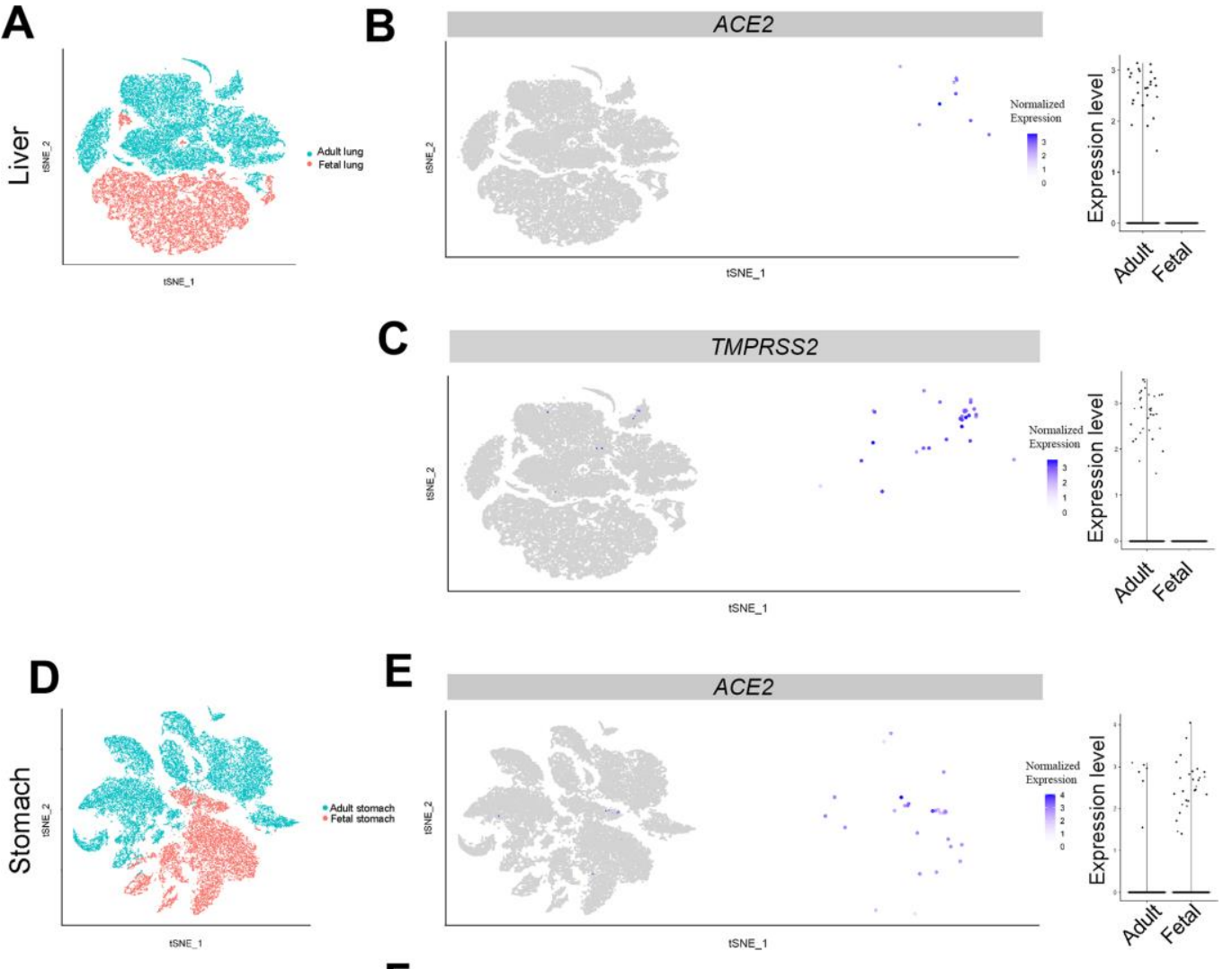

$\mathbf{F}$

TMPRSS2
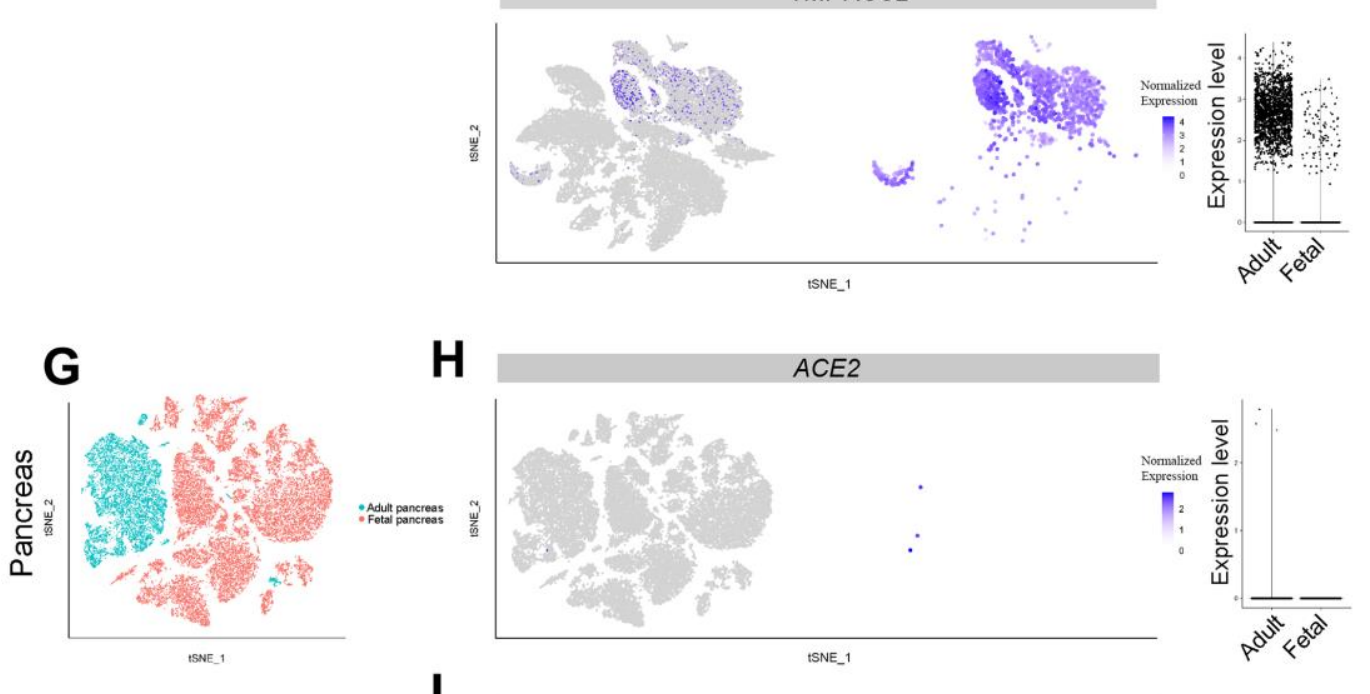

H

ACE2

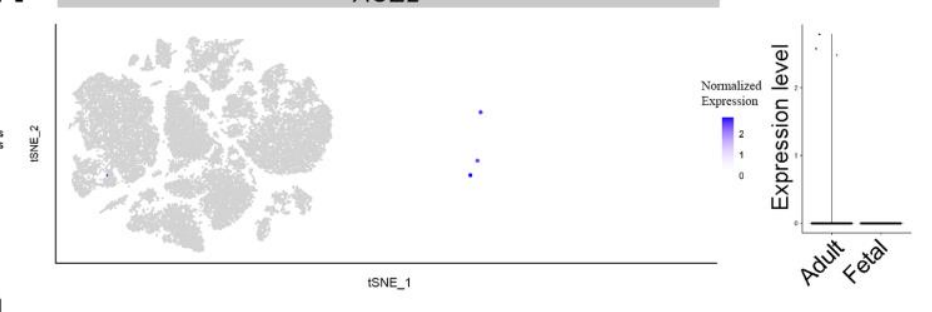

I

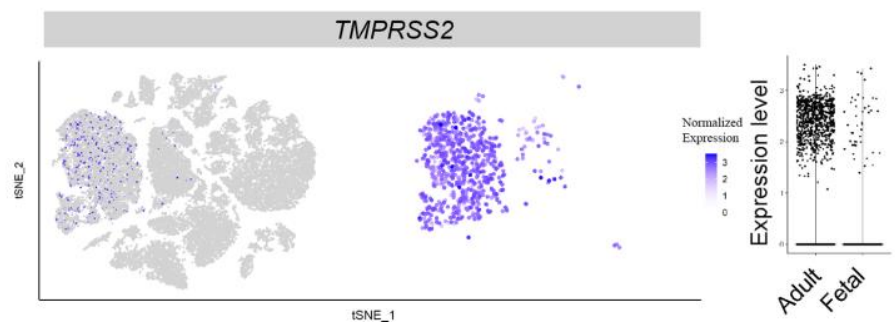

Figure 3. Single-cell analysis of liver, pancreas and stomach. (A) t-distributed stochastic neighbor embedding (TSNE) plot showing subclusters of liver cells, (B) ACE2 and (C) TMPRSS2 expression in liver from the adult and fetal groups. (D) TSNE plot showing sub-clusters of stomach cells, (E) ACE2 and (F) TMPRSS2 expression in stomach from the adult and fetal groups. (G) TSNE plot showing sub-clusters of pancreas cells, (H) ACE2 and (I) TMPRSS2 expression in pancreas from the adult and fetal groups. 
identify different cell clusters (Supplementary Figure $1 \mathrm{~F})$. The percentage of ACE2-expressing cells was lower in fetal than in adult heart tissues $(0.197 \%$ $(29 / 14,713)$ vs $0.564 \% \quad(68 / 12,063)$, respectively (Figure 4A, 4B, Figure 2). This result, together with previous reports $[28,29]$, suggested that SARSCoV-2 may directly infect myocardial cells and contribute to heart injury in adults and to a less extent in fetuses.

We further analyzed scRNA-seq data of muscle tissues obtained from one adult and one fetus. The data included 9,582 and 19,787 qualified cells, respectively. The ACE2-expressing cells were found only in adult muscle cells and were absent in fetal tissue (Figure 4C, 4D). In addition, the proportion of ACE2-positive cells was very low $(0.042 \%)$ compared with those of myocardial cells (Figure 2, Figure 4B), indicating muscle symptoms of COVID-19 patients may not directly result from SARS-CoV-2 infection.

\section{Cell clusters in fetal kidney and adrenal gland express both $A C E 2$ and TMPRSS2 genes}

Acute renal injury is associated with the higher mortality rate of COVID patients [30]. Therefore, the kidney appears susceptible to SARS-CoV-2 infection. In total, 57,034 single cells from publicly-available data, consisting of three adult and four fetal samples, were analyzed for ACE2 and TMPRSS2 expression at the single-cell level. Expression of PTPRC was used as a marker for immune cells, SLC34Al for proximal tubules, VCAM1 for parietal epithelial cells, ATP6V0D2 for collecting duct intercalated cells and SLC12A1 for cells of Henle's loop (Supplementary Figure 1H) [31, 32]. The expression of ACE2 was found mainly in proximal tubules of both adults and fetuses. The percentage of ACE2-expressing cells in the kidney was up to $2.736 \%$ among the 19,264 cells in the adult group, markedly higher than the other adult tissues. Fetal ACE2 expression reached $0.818 \%$, which was higher than the other fetal tissues (Figure $5 \mathrm{~A}$ and $5 \mathrm{~B}$, Figure 2). The expression of TMPRSS2 was mainly found in an ATP6VOD2-positive cluster in adults and widely expressed in fetal kidney cells (Figure 5A, 5C, Supplementary Figure 1H). These findings suggest that the kidney may be a main target for SARS-CoV-2 infection, beside the lungs, especially in the fetus.

Further analysis revealed that a relatively high percentage of fetal adrenal gland cells expressed ACE2 and TMPRSS2 (694 and 257 cells were positive, respectively, in 22,498 total fetal single cells); 91 cells expressed both ACE2 and TMPRSS2 (Figure 6). Most of the ACE2 and TMPRSS2-expressing cells were located
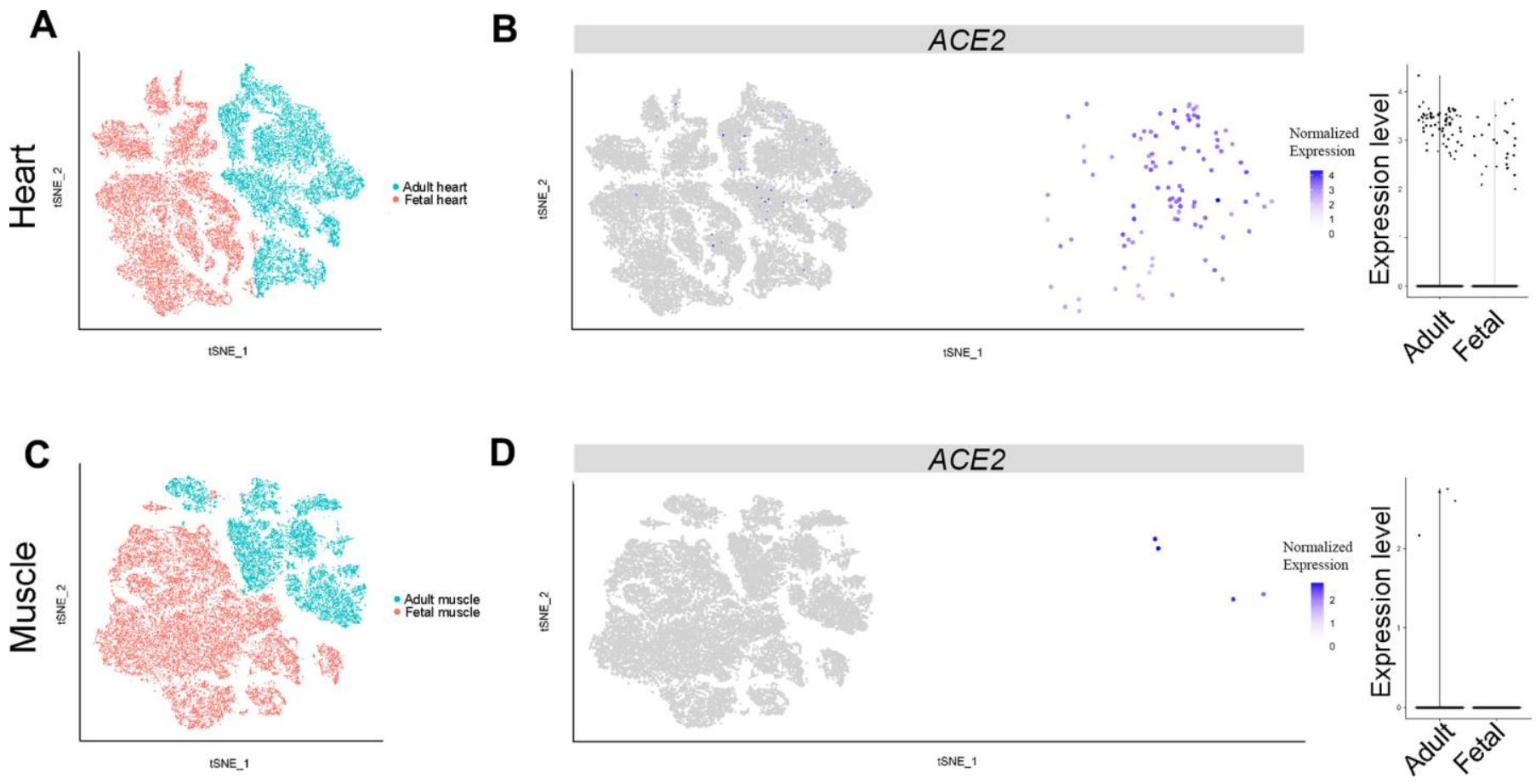

Figure 4. Single-cell analysis of heart and muscle. (A) t-distributed stochastic neighbor embedding (TSNE) plot showing sub-clusters of myocardial cells and (B) ACE2 expression in myocardial cells from the adult and fetal groups. (C) TSNE plot showing sub-clusters of muscle cells and (D) ACE2 expression in muscle from the adult and fetal groups. 
in the $E L F 3+$ cluster, which represents adrenal chromaffin cell precursors (Figure 5E, 5F, Supplementary Figure 1I) [33]. Furthermore, both ACE2 and TMPRSS2-expressing cells were absent in the adrenal gland cells from either adults or neonates (Figure 5E, 5F). Thus, SARS-CoV-2 likely infects the fetal adrenal gland, but not the gland in neonates and adults.

\section{DISCUSSION}

To evaluate the risk of vertical transmission and potential pathogenesis of SARS-CoV-2 infection in fetuses, we performed comparative single-cell analysis of ACE2 and TMPRSS2 expression in various adult and fetal tissues. We found that a few trophoblast cells expressed ACE2 in the placenta. The proportion of these cells was very low compared to other tissues, suggesting that the possibility of vertical transmission may be also very low. Further analysis of additional datasets also confirmed the low expression level of $A C E 2$ in placenta and other fetal organs (Supplementary Figure 2). However, SARS-CoV2 infection in newborn infants $[6,34,35]$ highlights that some unknow factors may enhance the possibility of vertical transmission. Thus, our study encourages further

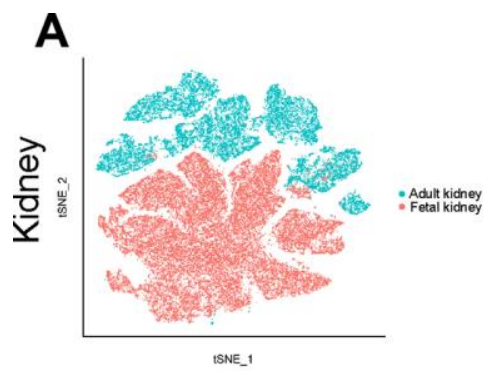

B

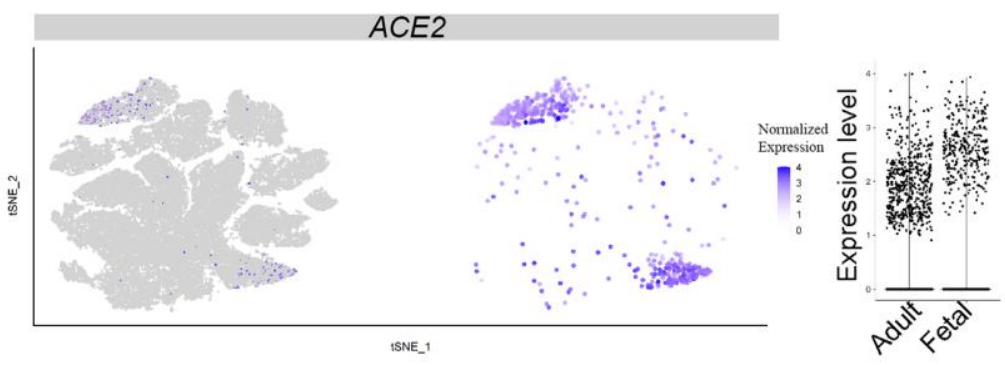

C
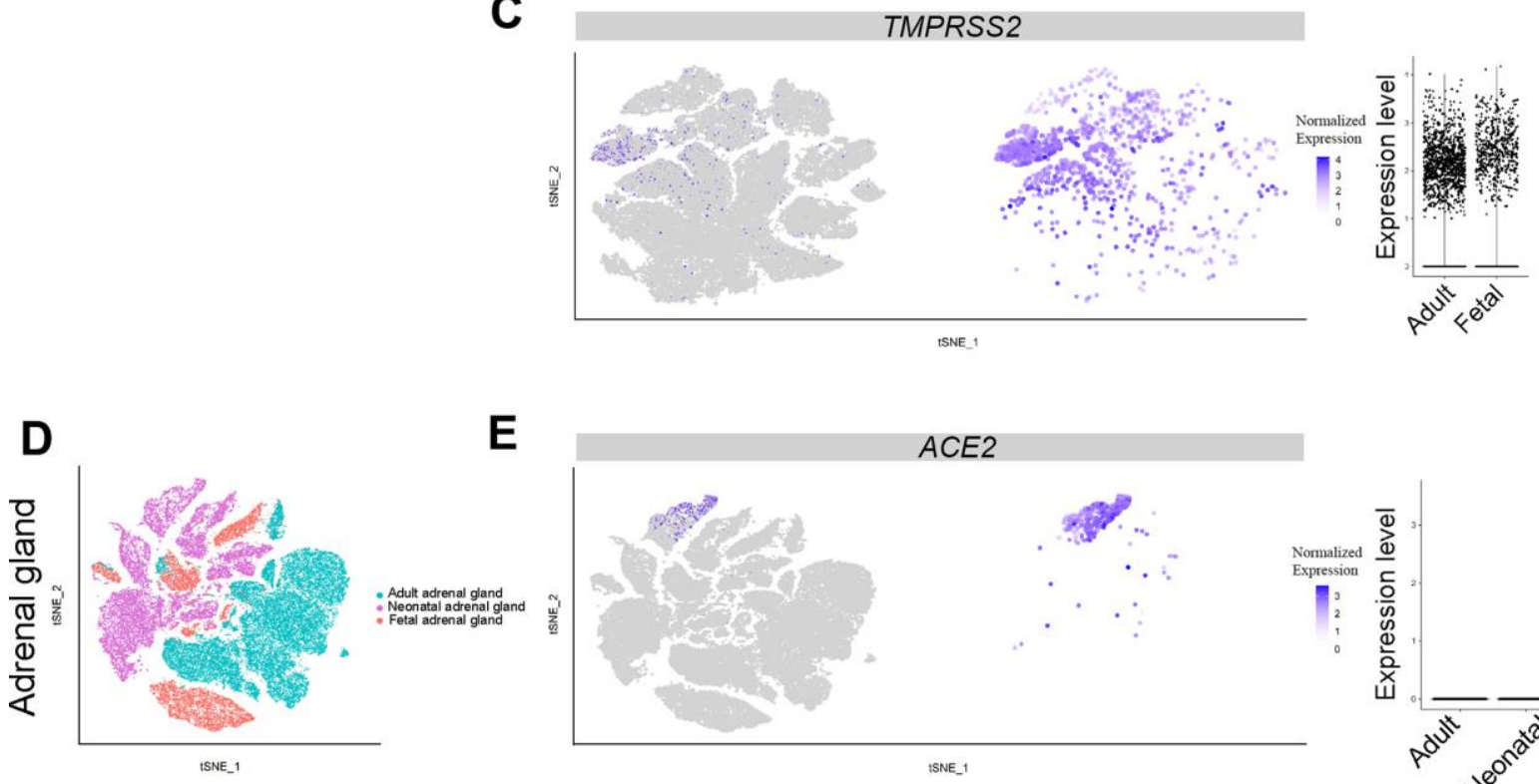

E
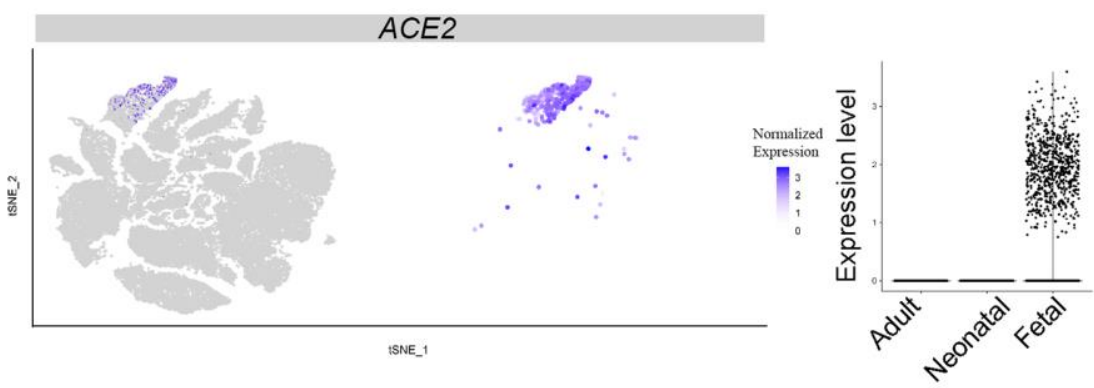

$\mathbf{F}$
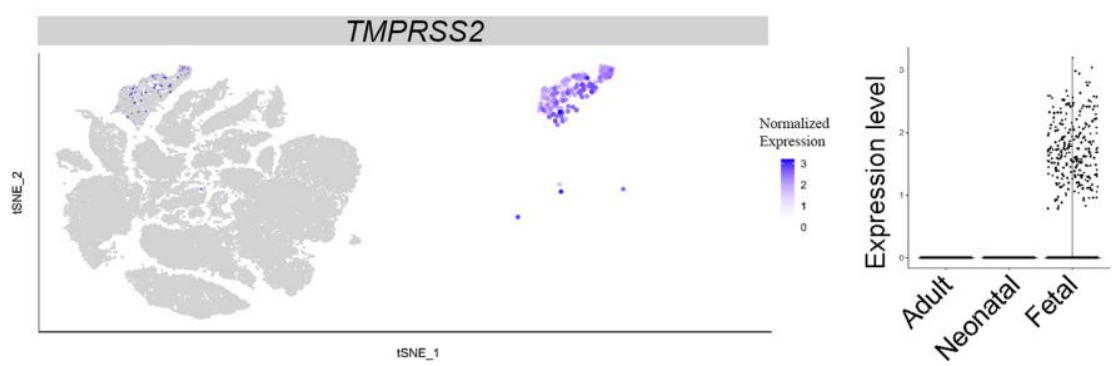

Figure 5. Single-cell analysis of adrenal gland and kidney. (A) t-distributed stochastic neighbor embedding (TSNE) plot showing subclusters of kidney cells, (B) ACE2 and (C) TMPRSS2 expression in kidney from the adult and fetal groups. (D) TSNE plot showing sub-clusters of adrenal gland cells, (E) ACE2 and (F) TMPRSS2 expression in adrenal gland from the adult, neonatal and fetal groups. 
investigation of the mechanisms underlying $A C E 2$ expression in trophoblast cells.

Consistent with previous studies [11, 12], we found ACE2-expressing cells were abundant in adult lungs AT2 cells. Surprisingly, ACE2-expressing cells were absent in fetal lungs, presumably resulting from the paucity of mature AT2 cells. Similarly, fetal liver lacked $A C E 2$-expression in $C A V 1$-positive clusters, which were present in adult liver. These results implied that fetal liver and lung tissues are not likely susceptible to SARS-CoV-2 infection.

Considering these findings, it is paradoxical that three out of 33 neonates were infected with SARS-CoV-2 when born to mothers with COVID-19. In particular, all three infected neonates had respiratory symptoms. One possibility is that lung $A C E 2$-expression is higher in the peri-natal period of development. Our study examined scRNA-seq data from fetal tissues collected from 7-27 weeks of gestation. In addition, ACE2 expression may be affected by oxygen concentration and other conditions, including smoking and inflammation [36]. Fetuses may not be harmed by the later environmental factors, perhaps explaining why ACE2 expression was absent in their AT2 equivalent cells.

Similar to that in adults, muscle in fetuses appears unlikely to be susceptible to SARS-CoV-2 infection because of the lack of ACE2-expressing cells.
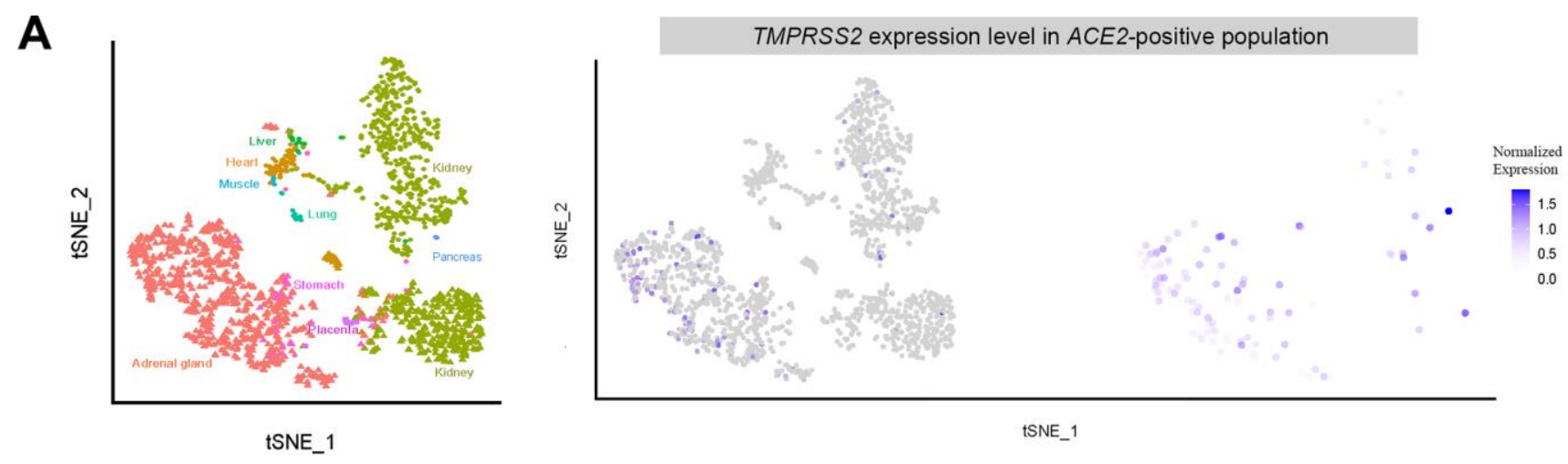

B
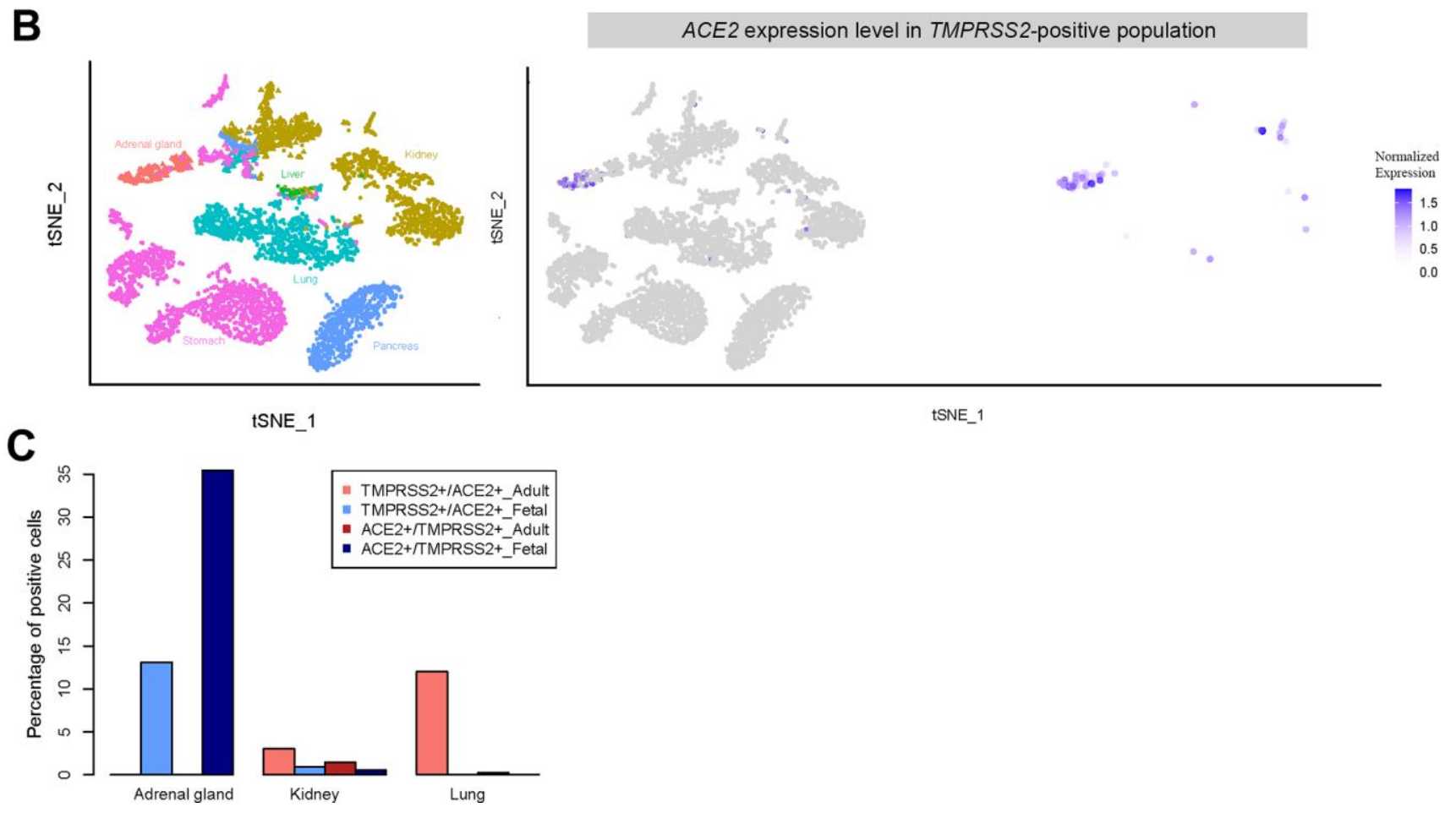

Figure 6. Expression of double positive (ACE2- and TMPRSS2- positive) and single positive (ACE2- or TMPRSS2- positive) cells. (A) t-distributed stochastic neighbor embedding (TSNE) plot displaying TMPRSS2 expression in ACE2-positive cells. (B) TSNE plot showing ACE2 expression in TMPRSS2-positive cells. (C) Percentage of double positive cells in each single positive population for the different tissues. 
Additionally, heart, kidney and stomach tissue from adults and fetuses all contained ACE2-expressing cells, suggesting SARS-CoV-2 infection may directly cause diarrhea and heart injury. Strikingly, a higher percentage of cells in the fetal adrenal gland and kidney expressed higher levels of both ACE2 and TMPRSS2 genes than those of adults. Thus, if vertical SARS-CoV2 infection occurs during pregnancy, infection most likely will cause injury to both the adrenal gland and kidney. Because the adrenal gland secretes several important hormones, the infection may harm fetal growth and development.

\section{MATERIALS AND METHODS}

\section{scRNA-seq datasets}

All the scRNA-seq datasets from adult and fetal tissues were acquired from the GEO database (Accession NO. GSE134355) [15]. Fetal tissues included two lungs, two heart, one muscle, two liver, four kidney, three adrenal gland, two stomach and three pancreas tissue samples. The neonatal samples included two adrenal gland tissues. The adult tissues included one placenta, three lungs, two heart, one muscle, five liver, three kidney, two adrenal gland, one pancreas and three stomach tissue samples. The GSM numbers of all these samples are listed in Table 1.

\section{Quality control}

Single-cell expression matrices were integrated for each tissue using "merge" function in the Seurat v3.1 R package [37]. Cells from lungs, liver and muscle tissues were filtered with a gene expression number per cell between 20 to 2500 , and a mitochondrial gene expression percent below 30. Myocardial cells were filtered with a gene expression number per cell between 20 to 1000 , and a mitochondrial percent below 30. Cells from adrenal gland and stomach tissues were filtered with a gene expression number per cell between 20 to 2500 , and a mitochondrial percent below 40. Cells from pancreas and placenta tissues were filtered with a gene expression number per cell between 20 to 2500, and a mitochondrial percent below 20. Cells from kidney were filtered with a gene expression number per cell between 20 to 2500, with a mitochondrial percent below 50 .

\section{Data processing}

The merged datasets were scaled by the "ScaleData" function with regression of the variation of mitochondrial genes. The expression matrix was then normalized using the "NormalizeData" function. The top 5,000 variable genes were selected with the "FindVariableFeatures" function in the Seurat package [37]. To overcome the extensive technical noise in any single feature for scRNA-seq data, principal components were chosen by running the "JackStrawPlot" function followed by the visualization function "ElbowPlot". Then, dimension reduction analysis was performed by the "RunPCA" function. The k-nearest neighbor graph based on the Euclidean distance was constructed using the "FindNeighbors" parameter, and cells were clustered by "FindClusters" with a ranged resolution from 0.3 to 0.7 . Gene expression visualization based on non-linear dimensional reduction was shown by "DimPlot" and "FeaturePlot" parameters, and violin plots were obtained by the "VlnPlot" function.

\section{AUTHOR CONTRIBUTIONS}

Q. L., R. G. and M. L. designed this research. Q. L. supervised this project. M. L. did the data analysis and figure visualization. M. L. and R. G. drafted the manuscript. Q. L., R. G., M. L., G. J. and L. Q. revised the manuscript.

\section{CONFLICTS OF INTEREST}

The authors declare no conflicts of interest.

\section{FUNDING}

This work was supported by the National Key Project for Infectious Diseases of China (2018ZX10301-208), the start-up fund of Nanshan Scholarship of Guangzhou Medical University, the Guangzhou Key Medical Discipline Construction Project Fund and Postdoctoral Research Start-up Funding of the First Affiliated Hospital of Zhengzhou University (R. G.).

\section{REFERENCES}

1. Guan WJ, Ni ZY, Hu Y, Liang WH, Ou CQ, He JX, Liu L, Shan H, Lei CL, Hui DS, Du B, Li L, Zeng G, et al, and China Medical Treatment Expert Group for Covid-19. Clinical characteristics of coronavirus disease 2019 in China. N Engl J Med. 2020; 382:1708-20. https://doi.org/10.1056/NEJMoa2002032 PMID:32109013

2. Shi S, Qin M, Shen B, Cai Y, Liu T, Yang F, Gong W, Liu X, Liang J, Zhao Q, Huang H, Yang B, Huang C. Association of cardiac injury with mortality in hospitalized patients with COVID-19 in Wuhan, China. JAMA Cardiol. 2020; 5:802-10. https://doi.org/10.1001/jamacardio.2020.0950 PMID: $\underline{32211816}$

3. Yao XH, Li TY, He ZC, Ping YF, Liu HW, Yu SC, Mou HM, Wang LH, Zhang HR, Fu WJ, Luo T, Liu F, Guo QN, et al. 
[A pathological report of three COVID-19 cases by minimal invasive autopsies]. Zhonghua Bing Li Xue Za Zhi. 2020; 49:411-17.

https://doi.org/10.3760/cma.j.cn112151-2020031200193 PMID:32172546

4. Hanley B, Lucas SB, Youd E, Swift B, Osborn M. Autopsy in suspected COVID-19 cases. J Clin Pathol. 2020; 73:239-42.

https://doi.org/10.1136/iclinpath-2020-206522 PMID:32198191

5. Wei M, Yuan J, Liu Y, Fu T, Yu X, Zhang ZJ. Novel coronavirus infection in hospitalized infants under 1 year of age in China. JAMA. 2020; 323:1313-14. https://doi.org/10.1001/jama.2020.2131 PMID:32058570

6. Dong L, Tian J, He S, Zhu C, Wang J, Liu C, Yang J. Possible vertical transmission of SARS-CoV-2 from an infected mother to her newborn. JAMA. 2020; 323:1846-48.

https://doi.org/10.1001/jama.2020.4621 PMID:32215581

7. Wang M, Hu Z. Bats as animal reservoirs for the SARS coronavirus: hypothesis proved after 10 years of virus hunting. Virol Sin. 2013; 28:315-17. https://doi.org/10.1007/s12250-013-3402-x PMID:24174406

8. Ge XY, Li JL, Yang XL, Chmura AA, Zhu G, Epstein JH, Mazet JK, Hu B, Zhang W, Peng C, Zhang YJ, Luo CM, Tan $B$, et al. Isolation and characterization of a bat SARS-like coronavirus that uses the ACE2 receptor. Nature. 2013; 503:535-38. https://doi.org/10.1038/nature12711 PMID:24172901

9. Zhou $P$, Yang $X L$, Wang $X G$, Hu B, Zhang L, Zhang $W$, Si HR, Zhu Y, Li B, Huang CL, Chen HD, Chen J, Luo Y, et al. A pneumonia outbreak associated with a new coronavirus of probable bat origin. Nature. 2020; 579:270-73.

https://doi.org/10.1038/s41586-020-2012-7 PMID:32015507

10. Hoffmann $M$, Kleine-Weber $H$, Schroeder $S$, Krüger $N$, Herrler T, Erichsen S, Schiergens TS, Herrler G, Wu NH, Nitsche A, Müller MA, Drosten C, Pöhlmann S. SARSCoV-2 cell entry depends on ACE2 and TMPRSS2 and is blocked by a clinically proven protease inhibitor. Cell. 2020; 181:271-80.e8. https://doi.org/10.1016/i.cell.2020.02.052 PMID:32142651

11. Zou X, Chen K, Zou J, Han P, Hao J, Han Z. Single-cell RNA-seq data analysis on the receptor ACE2 expression reveals the potential risk of different human organs vulnerable to 2019-nCoV infection. Front Med. 2020; 14:185-92. https://doi.org/10.1007/s11684-020-0754-0 PMID:32170560

12. Zhao $Y$, Zhao Z, Wang $Y$, Zhou $Y$, Ma $Y$, Zuo W. Singlecell RNA expression profiling of ACE2, the receptor of SARS-CoV-2. Am J Respir Crit Care Med. 2020. [Epub ahead of print]. https://doi.org/10.1164/rccm.202001-0179LE PMID: $\underline{32663409}$

13. WU $C$, Zheng $S$, Chen $Y$, Zheng $M$. Single-cell RNA expression profiling of ACE2, the putative receptor of Wuhan 2019-nCoV, in the nasal tissue. medRxiv. https://doi.org/10.1101/2020.02.11.20022228

14. Chen N, Zhou M, Dong X, Qu J, Gong F, Han Y, Qiu Y, Wang J, Liu Y, Wei Y, Xia J, Yu T, Zhang X, Zhang L. Epidemiological and clinical characteristics of 99 cases of 2019 novel coronavirus pneumonia in Wuhan, China: a descriptive study. Lancet. 2020; 395:507-13.

https://doi.org/10.1016/S0140-6736(20)30211-7 PMID:32007143

15. Han X, Zhou Z, Fei L, Sun $H$, Wang R, Chen $Y$, Chen $H$, Wang J, Tang $\mathrm{H}, \mathrm{Ge} W$, Zhou $Y$, Ye F, Jiang $M$, et al. Construction of a human cell landscape at single-cell level. Nature. 2020; 581:303-09. https://doi.org/10.1038/s41586-020-2157-4 PMID:32214235

16. Liu $Y$, Fan $X$, Wang R, Lu X, Dang YL, Wang H, Lin HY, Zhu $C$, Ge $H$, Cross JC, Wang $H$. Single-cell RNA-seq reveals the diversity of trophoblast subtypes and patterns of differentiation in the human placenta. Cell Res. 2018; 28:819-32.

https://doi.org/10.1038/s41422-018-0066-y PMID:30042384

17. Lv $B$, An $Q$, Zeng $Q$, Zhang $X$, Lu $P$, Wang $Y$, Zhu X, Ji Y, Fan $G$, Xue $Z$. Single-cell RNA sequencing reveals regulatory mechanism for trophoblast cell-fate divergence in human peri-implantation conceptuses. PLoS Biol. 2019; 17:e3000187.

https://doi.org/10.1371/journal.pbio.3000187 PMID:31596842

18. Tsuchida N, Kojima J, Fukuda A, Oda M, Kawasaki T, Ito H, Kuji N, Isaka K, Nishi H, Umezawa A, Akutsu H. Transcriptomic features of trophoblast lineage cells derived from human induced pluripotent stem cells treated with BMP 4. Placenta. 2020; 89:20-32.

https://doi.org/10.1016/j.placenta.2019.10.006 PMID:31675487

19. Vivanti AJ, Vauloup-Fellous C, Prevot S, Zupan V, Suffee C, Do Cao J, Benachi A, De Luca D. Transplacental transmission of SARS-CoV-2 infection. Nat Commun. 2020; 11:3572.

https://doi.org/10.1038/s41467-020-17436-6

PMID:32665677 
20. Bayer A, Lennemann NJ, Ouyang $Y$, Bramley JC, Morosky S, Marques ET Jr, Cherry S, Sadovsky Y, Coyne CB. Type III interferons produced by human placental trophoblasts confer protection against zika virus infection. Cell Host Microbe. 2016; 19:705-12.

https://doi.org/10.1016/i.chom.2016.03.008 PMID:27066743

21. McElroy MC, Kasper M. The use of alveolar epithelial type I cell-selective markers to investigate lung injury and repair. Eur Respir J. 2004; 24:664-73. https://doi.org/10.1183/09031936.04.00096003 PMID:15459148

22. Hawkins F, Kramer $P$, Jacob A, Driver I, Thomas DC, McCauley KB, Skvir N, Crane AM, Kurmann AA, Hollenberg AN, Nguyen S, Wong BG, Khalil AS, et al. Prospective isolation of NKX2-1-expressing human lung progenitors derived from pluripotent stem cells. J Clin Invest. 2017; 127:2277-94. https://doi.org/10.1172/JCl89950 PMID:28463226

23. Lambrechts D, Wauters E, Boeckx B, Aibar S, Nittner D, Burton O, Bassez A, Decaluwé $H$, Pircher A, Van den Eynde K, Weynand B, Verbeken E, De Leyn P, et al. Phenotype molding of stromal cells in the lung tumor microenvironment. Nat Med. 2018; 24:1277-89.

https://doi.org/10.1038/s41591-018-0096-5 PMID:29988129

24. Zhang C, Shi L, Wang FS. Liver injury in COVID-19: management and challenges. Lancet Gastroenterol Hepatol. 2020; 5:428-30.

https://doi.org/10.1016/S2468-1253(20)30057-1 PMID:32145190

25. Segal JM, Kent D, Wesche DJ, Ng SS, Serra M, Oulès B, Kar G, Emerton G, Blackford SJ, Darmanis S, Miquel R, Luong TV, Yamamoto $R$, et al. Single cell analysis of human foetal liver captures the transcriptional profile of hepatobiliary hybrid progenitors. Nat Commun. 2019; 10:3350.

https://doi.org/10.1038/s41467-019-11266-x PMID:31350390

26. Jun Wang SZ, Ming Liu, Zhiyao Zhao, Yiping Xu, Ping Wang, Meng Lin, Yanhui Xu, Bing Huang, Xiaoyu Zuo, Zhanghua Chen, Fan Bai, Jun Cui, Andrew M Lew, et al. ACE2 expression by colonic epithelial cells is associated with viral infection, immunity and energy metabolism. medRxiv. 2020.

https://doi.org/10.1101/2020.02.05.20020545

27. Zhang $P$, Yang $M$, Zhang $Y$, Xiao S, Lai X, Tan A, Du S, Li $S$. Dissecting the single-cell transcriptome network underlying gastric premalignant lesions and early gastric cancer. Cell Rep. 2019; 27:1934-47.e5. https://doi.org/10.1016/i.celrep.2019.04.052 PMID:31067475
28. Wei ZY, Qian HY. [Myocardial injury in patients with COVID-19 pneumonia]. Zhonghua Xin Xue Guan Bing Za Zhi. 2020; 48:E006.

https://doi.org/10.3760/cma.j.issn.cn11214820200220-00106 PMID:32118393

29. Li B, Yang J, Zhao F, Zhi L, Wang X, Liu L, Bi Z, Zhao Y. Prevalence and impact of cardiovascular metabolic diseases on COVID-19 in China. Clin Res Cardiol. 2020; 109:531-38.

https://doi.org/10.1007/s00392-020-01626-9 PMID: $\underline{32161990}$

30. Rismanbaf A, Zarei S. Liver and kidney injuries in COVID-19 and their effects on drug therapy; a letter to editor. Arch Acad Emerg Med. 2020; 8:e17. PMID:32185369

31. Wilson PC, Wu H, Kirita $Y$, Uchimura K, Ledru N, Rennke HG, Welling PA, Waikar SS, Humphreys BD. The single-cell transcriptomic landscape of early human diabetic nephropathy. Proc Natl Acad Sci USA. 2019; 116:19619-25.

https://doi.org/10.1073/pnas.1908706116 PMID:31506348

32. Young MD, Mitchell TJ, Vieira Braga FA, Tran MG, Stewart BJ, Ferdinand JR, Collord G, Botting RA, Popescu DM, Loudon KW, Vento-Tormo R, Stephenson E, Cagan A, et al. Single-cell transcriptomes from human kidneys reveal the cellular identity of renal tumors. Science. 2018; 361:594-99.

https://doi.org/10.1126/science.aat1699 PMID:30093597

33. Chan WH, Komada $M$, Fukushima $T$, Southard-Smith EM, Anderson CR, Wakefield MJ. RNA-seq of isolated chromaffin cells highlights the role of sex-linked and imprinted genes in adrenal medulla development. Sci Rep. 2019; 9:3929. https://doi.org/10.1038/s41598-019-40501-0 PMID: $\underline{30850723}$

34. Zeng L, Xia S, Yuan W, Yan K, Xiao F, Shao J, Zhou W. Neonatal early-onset infection with SARS-CoV-2 in 33 neonates born to mothers with COVID-19 in Wuhan, China. JAMA Pediatr. 2020; 174:722-25.

https://doi.org/10.1001/jamapediatrics.2020.0878 PMID:32215598

35. Yu N, Li W, Kang Q, Xiong Z, Wang S, Lin X, Liu Y, Xiao J, Liu H, Deng D, Chen S, Zeng W, Feng L, Wu J. Clinical features and obstetric and neonatal outcomes of pregnant patients with COVID-19 in Wuhan, China: a retrospective, single-centre, descriptive study. Lancet Infect Dis. 2020; 20:559-64.

https://doi.org/10.1016/S1473-3099(20)30176-6 PMID:32220284

36. Clarke NE, Belyaev ND, Lambert DW, Turner AJ. Epigenetic regulation of angiotensin-converting 
enzyme 2 (ACE2) by SIRT1 under conditions of cell energy stress. Clin Sci (Lond). 2014; 126:507-16. https://doi.org/10.1042/CS20130291 PMID:24147777

37. Stuart T, Butler A, Hoffman P, Hafemeister C, Papalexi E, Mauck WM 3rd, Hao Y, Stoeckius M, Smibert P,
Satija R. Comprehensive integration of single-cell data. Cell. 2019; 177:1888-902.e21.

https://doi.org/10.1016/j.cell.2019.05.031

PMID:31178118 


\section{SUPPLEMENTARY MATERIALS}

\section{Supplementary Figures}

A
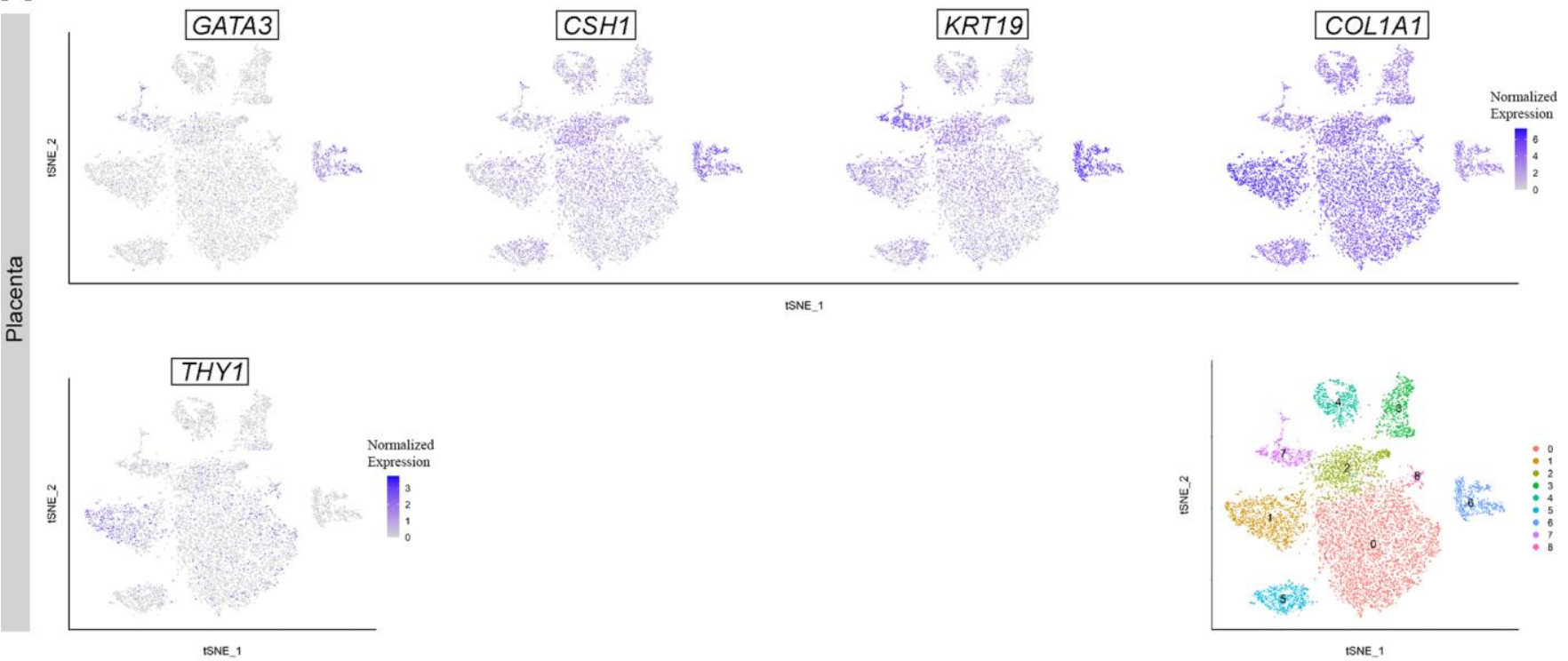

B
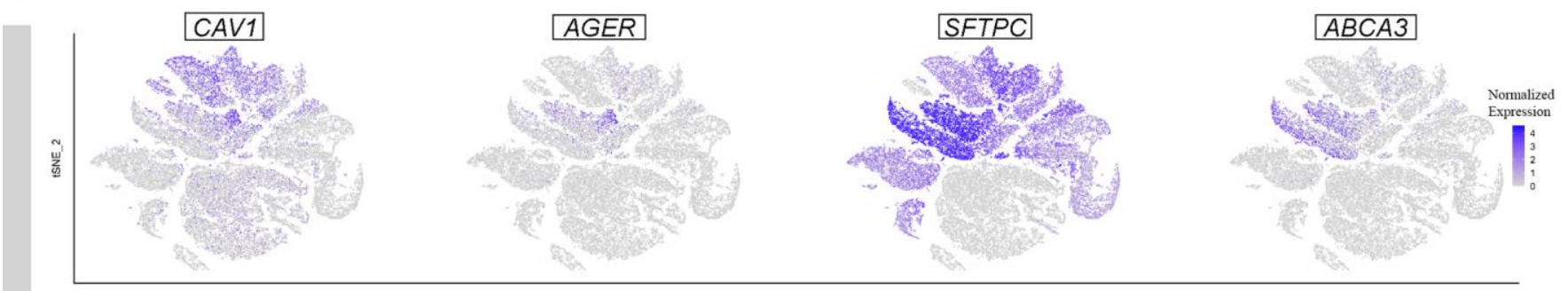

ISNE_1
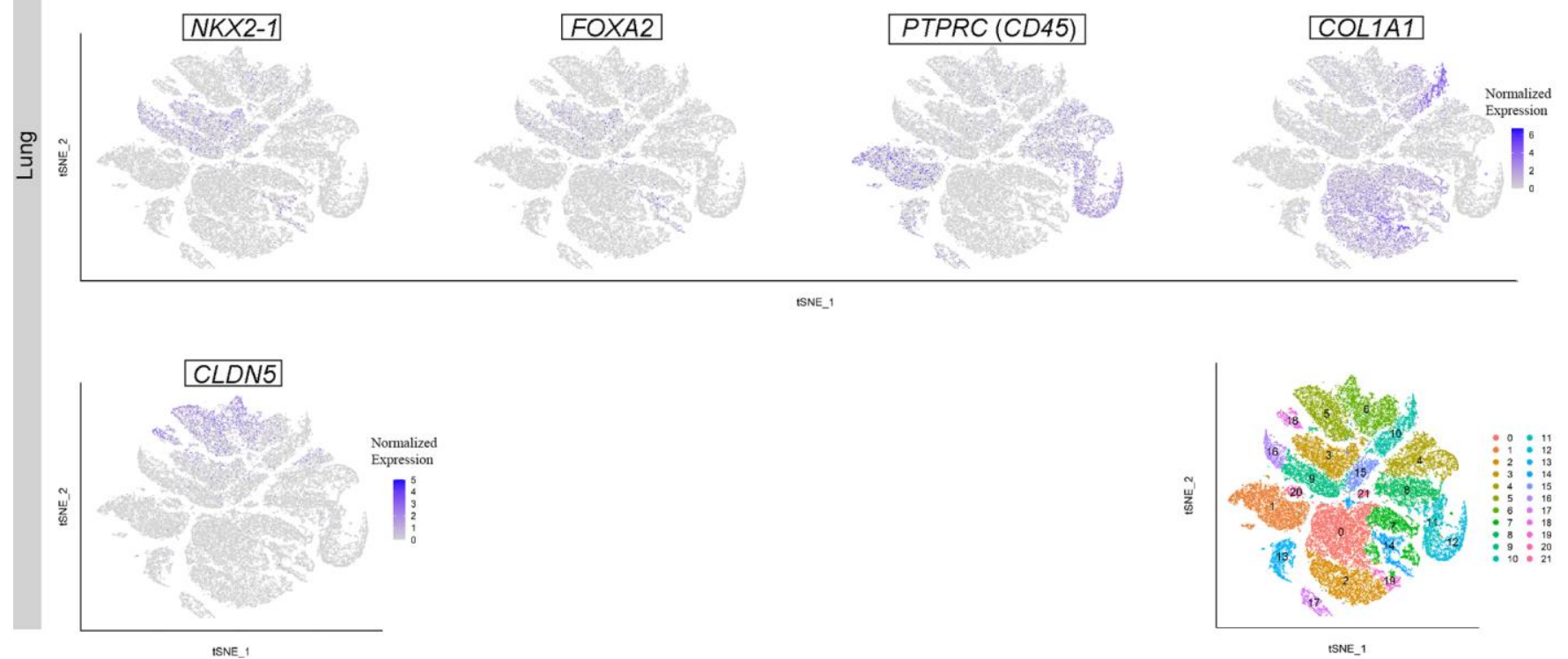


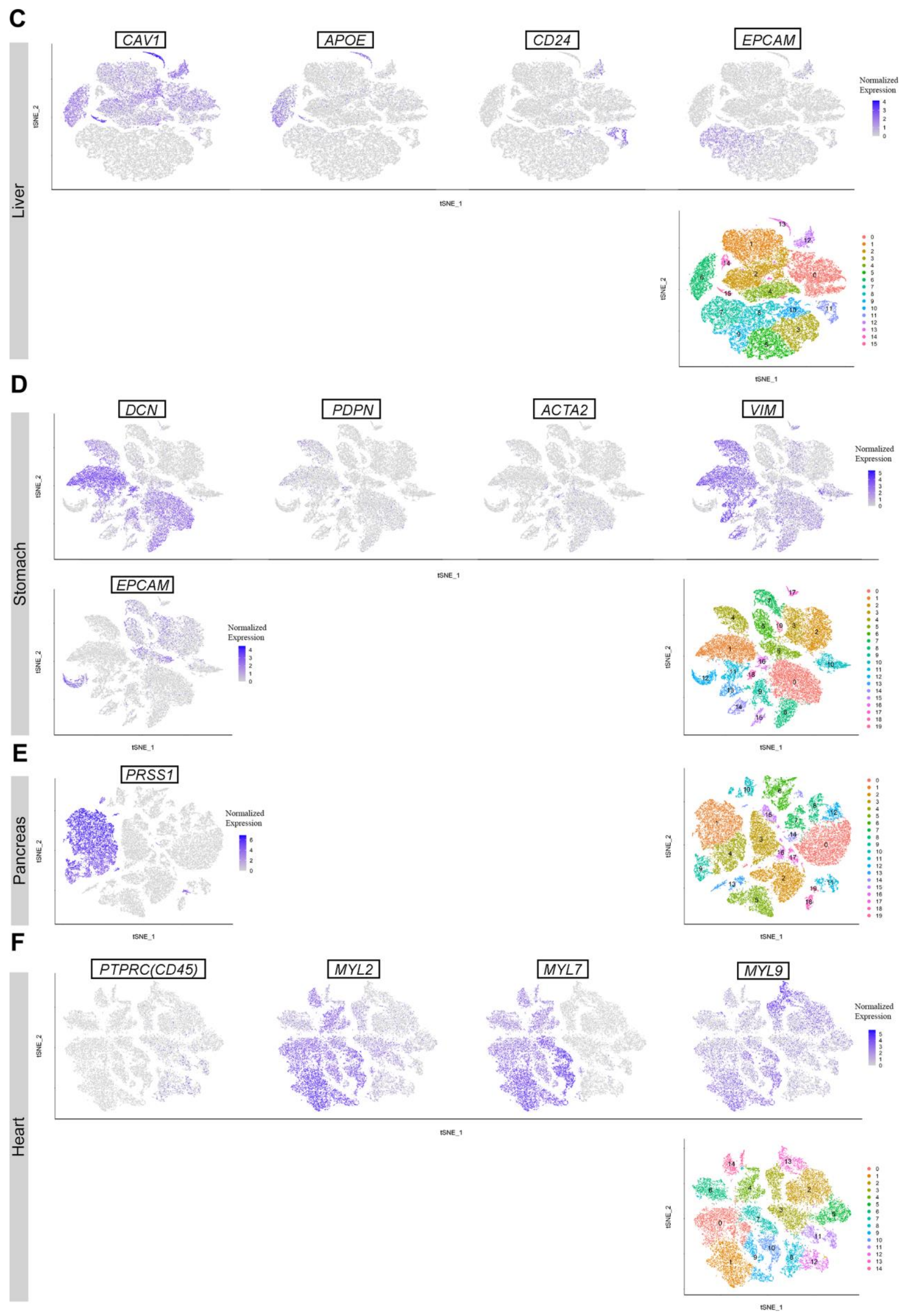



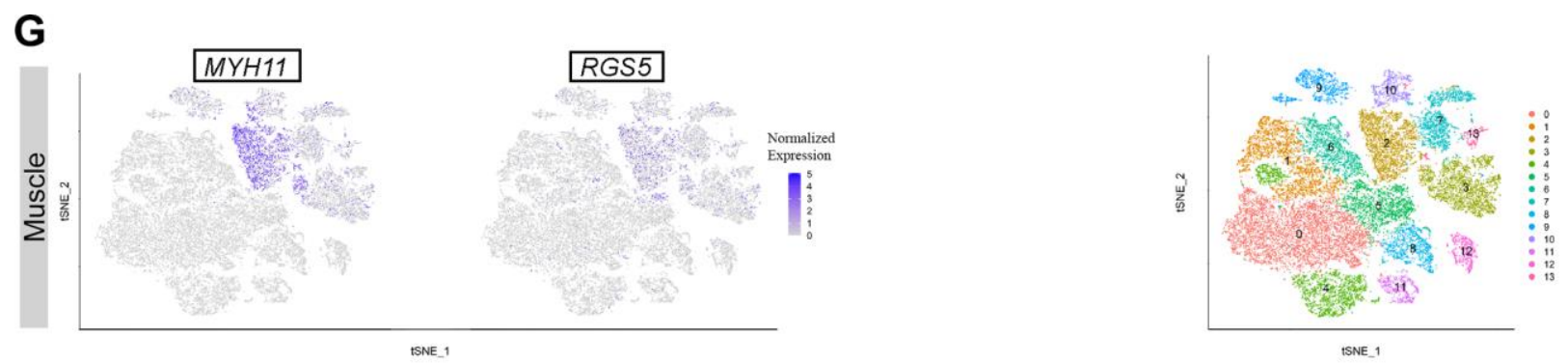

\section{H}
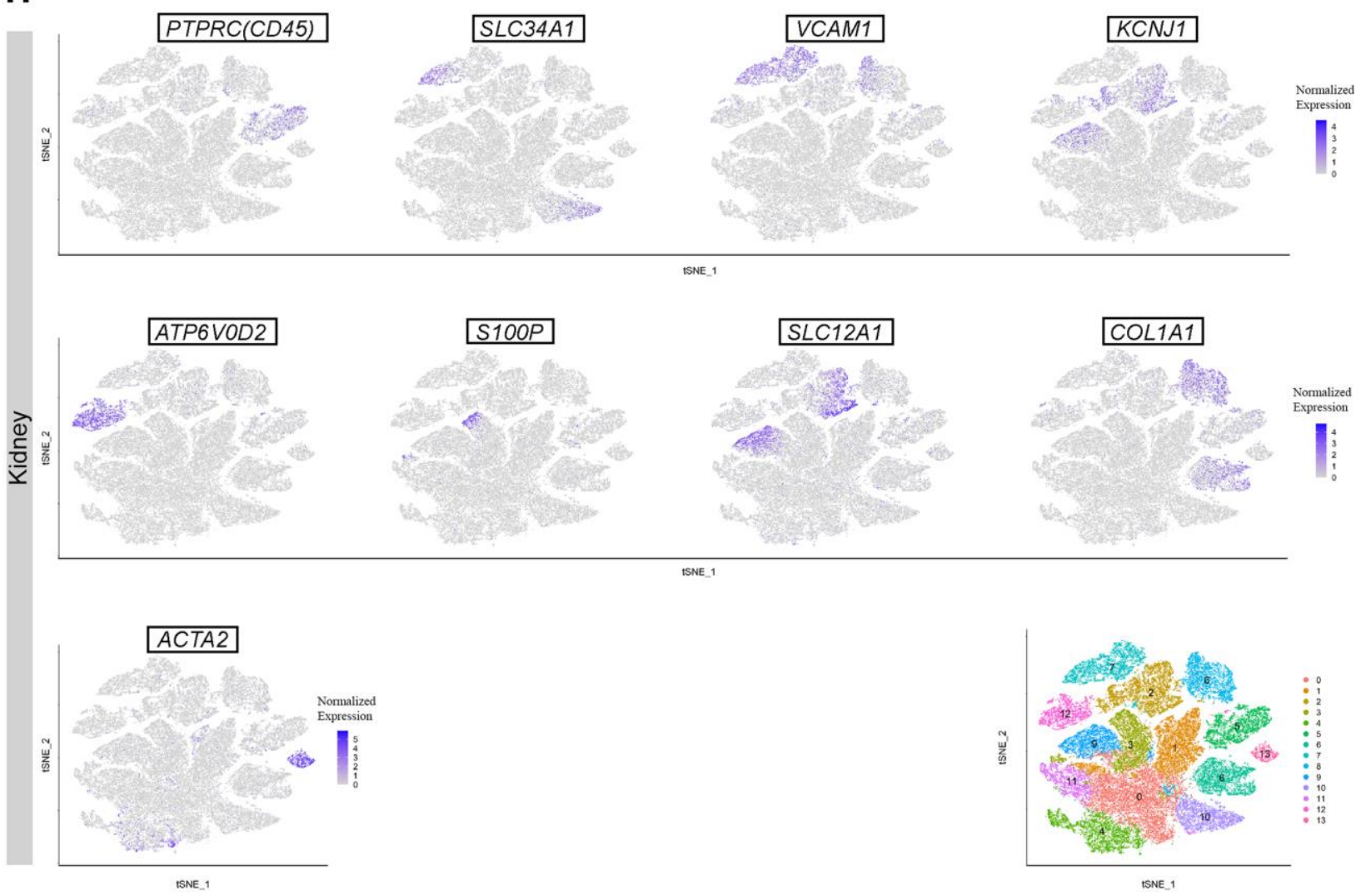

I
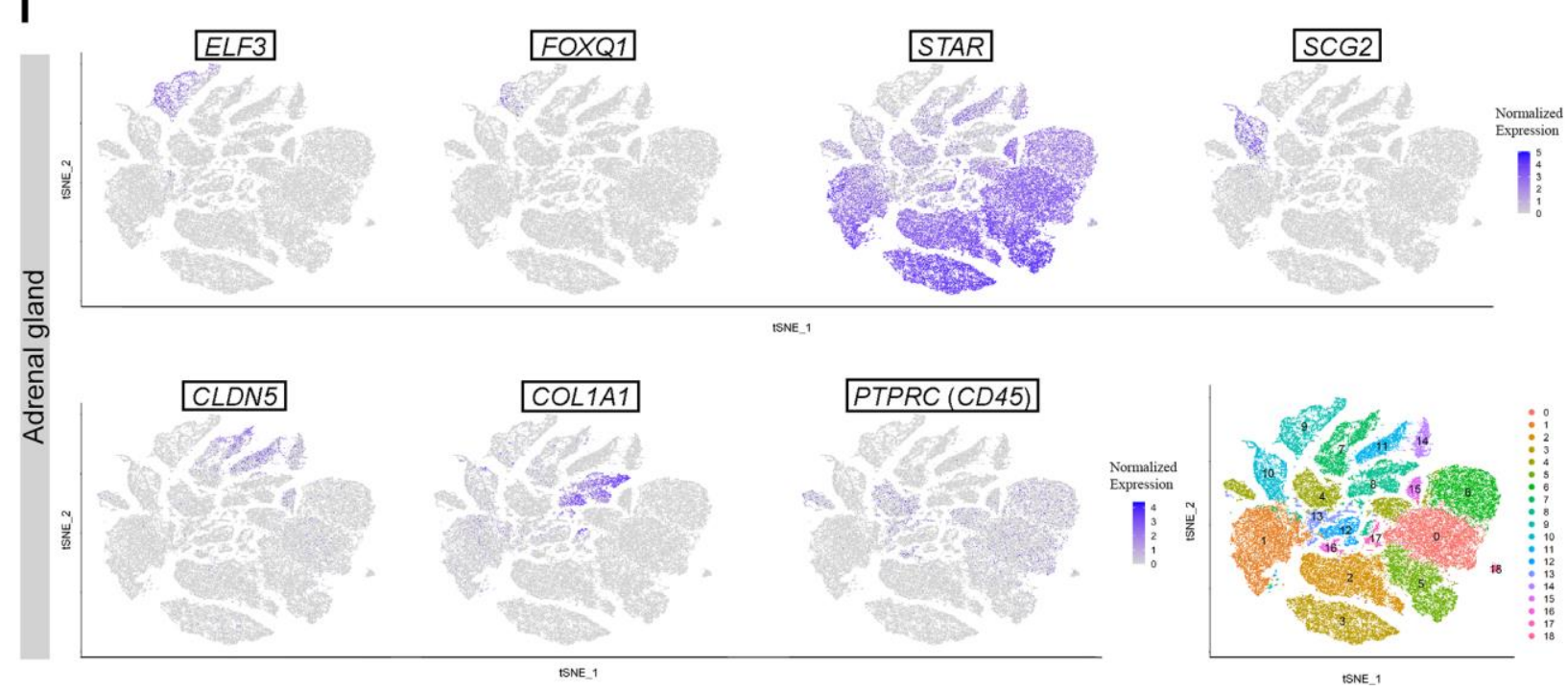

Supplementary Figure 1. Single-cell markers of each tissue. t-distributed stochastic neighbor embedding plot displaying cell markers of (A) placenta, (B) lungs, (C) liver, (D) stomach, (E) pancreas, (F) heart, (G) muscle, (H) kidney and (I) adrenal gland tissues. 

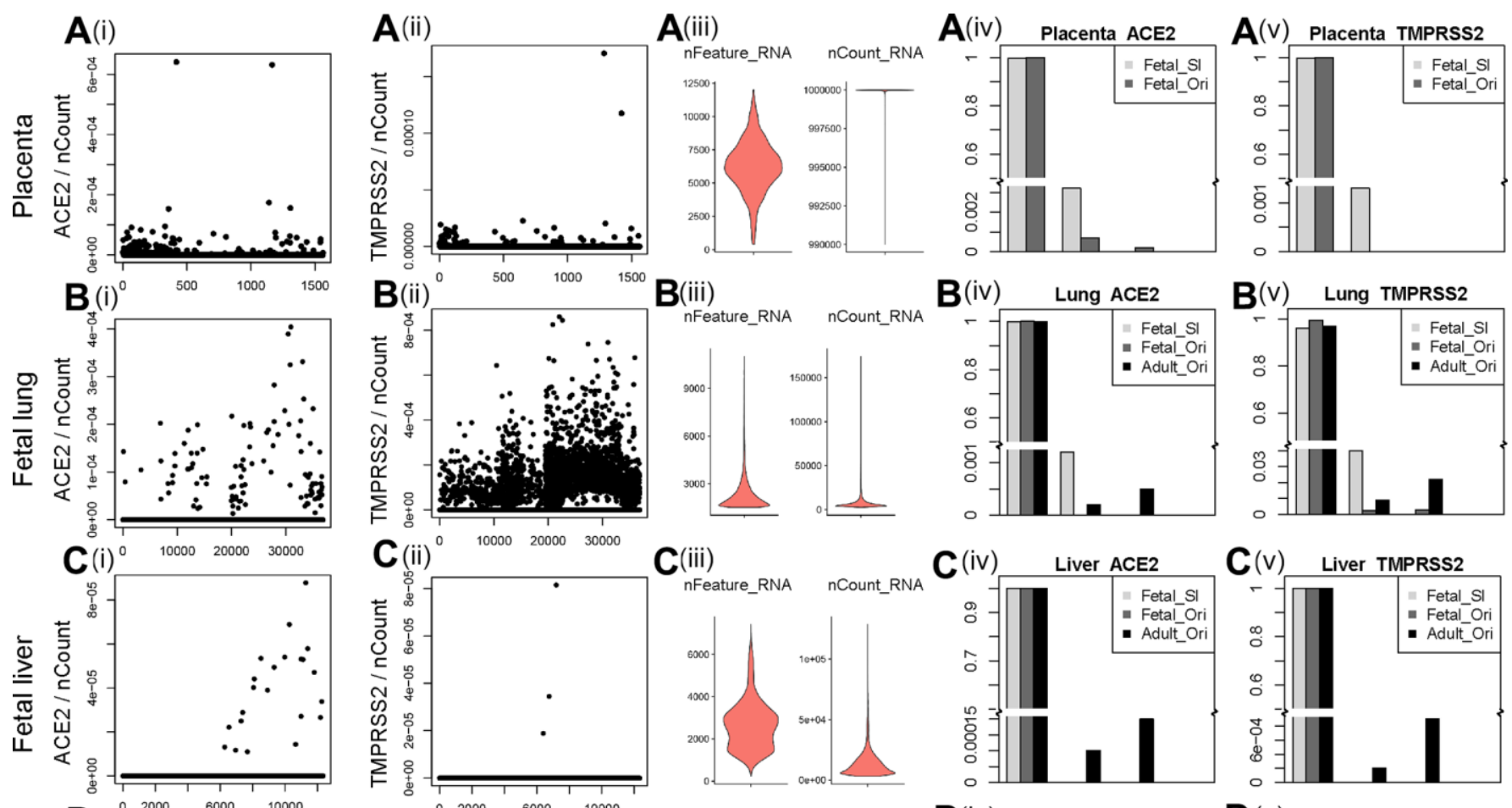

C(iii)
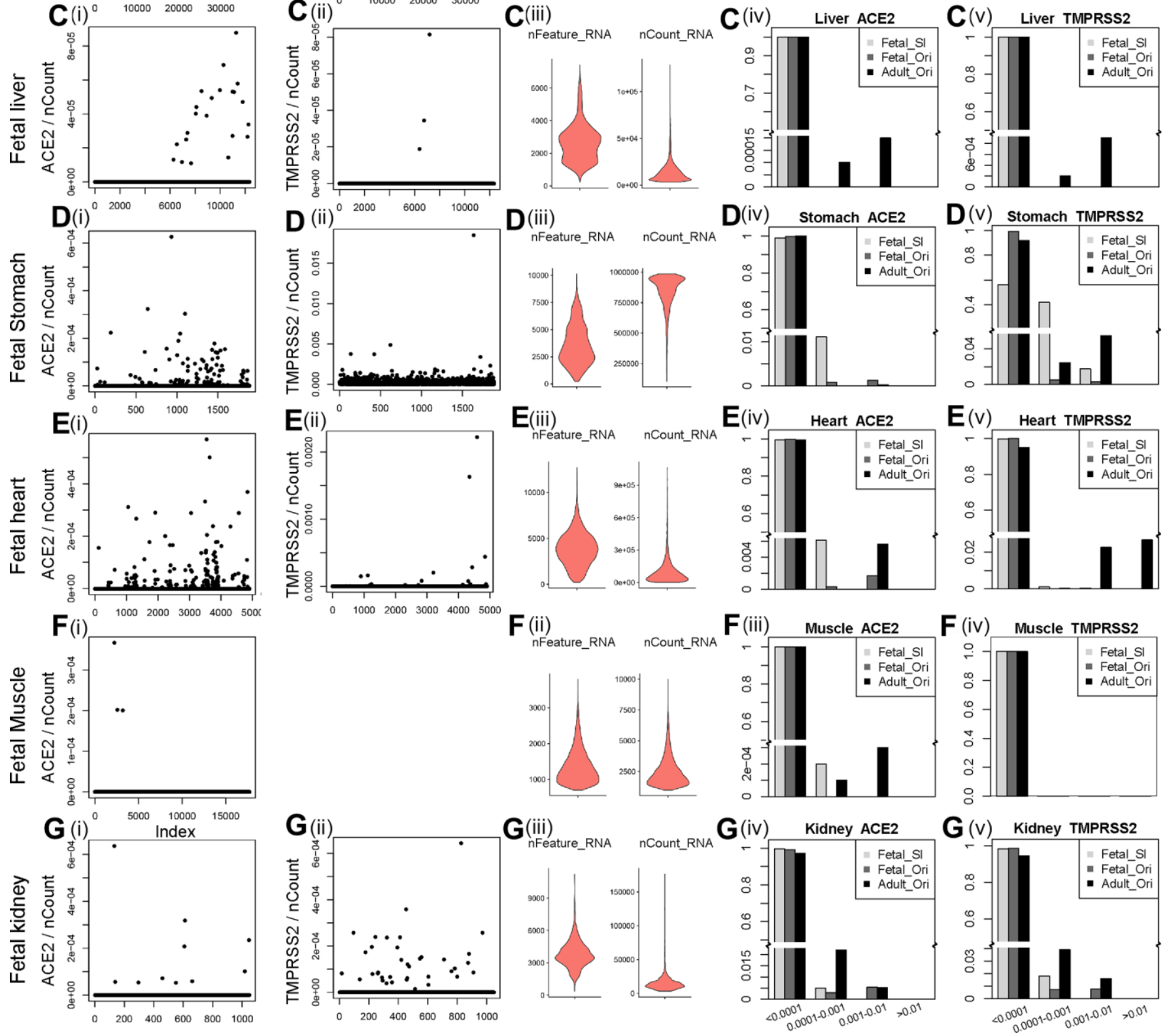

Supplementary Figure 2. ACE2 and TMPRSS2 expression levels in fetal tissues. A (i), B (i), C (i), D (i), E (i), F (i) and G (i) show the proportion of $A C E 2$ read counts versus total read counts in placenta, and fetal lungs, liver, stomach, heart, muscle and kidney, respectively. A 
(ii), B (ii), C (ii), D (ii), E (ii), and G (ii) show the proportion of TMPRSS2 read counts versus total read counts in placenta, and fetal lungs, liver, stomach, heart, muscle and kidney. A (iii), B (iii), C (iii), D (iii), E (iii), F (ii) and G (iii) show gene features and RNA counts detected in single-cell RNA sequencing data. A (iv), B (iv), C (iv), D (iv), $\mathbf{E}$ (iv), $\mathbf{F}$ (iii) and $\mathbf{G}$ (iv) summarize the ACE2 expression level in each tissue, where Fetal_SI stands for the supplementary datasets of fetal tissue (refer to Supplementary Table 1), and Fetal_Ori and Adult_Ori stand for the datasets used in the manuscript. A (v), B (v), C (v), D (v), E (v), F (iv) and G (v) summarize the TMPRSS2 expression level in each tissue, where Fetal_SI stands for the supplementary datasets of fetal tissue (refer to Supplementary Table 1), and Fetal_Ori and Adult_Ori stand for the datasets used in the manuscript.

\section{Supplementary Table}

Supplementary Table 1. Expression level of ACE2 in placenta and other fetal organs.

\begin{tabular}{lcc}
\hline Organs/Tissues & ID & Database \\
\hline Fetal heart & GSE106118 & GEO \\
Fetal muscle & GSE147457 & GEO \\
Fetal lung & E-MTAB-8821 & EMBL-EBI \\
Placenta & GSE89497 & GEO \\
Fetal kidney & 4834 STDY7002881 & EMBL-EBI \\
& FCAImmP7292032 & EMBL-EBI \\
Fetal liver & 4834STDY7002882 & EMBL-EBI \\
& FCAImmP7198434 & EMBL-EBI \\
\hline
\end{tabular}

